\title{
BUSINESS ETHICS IN A TRANSFORMING ECONOMY: APPLYING THE INTEGRATIVE SOCIAL CONTRACTS THEORY TO RUSSIA ${ }^{+}$
}

\author{
SHEIla M. PufFeR ${ }^{*} \&$ DanIEL J. MCCARTHY ${ }^{*}$
}

\section{INTRODUCTION}

Russia's economic transition in the past decade from a centrally-planned to a market-oriented economy has occurred within a dramatically changing political, social, and cultural context. The biggest shift occurred in late 1991, when more than seven decades of communist rule came to a swift end, the former U.S.S.R. was dissolved, and Russia started on a new course toward a more democratic political system and a market-oriented economy.

With these changes, many new ideas, attitudes, and practices have emerged; yet, numerous influences from the past continue to affect the thoughts and behavior of most Russians. ${ }^{1}$ These converging forces have evoked much uncertainty regarding the interpretation of what constitutes ethically acceptable behavior for Russians, including those involved in business. In this confusing

+ This Article is also being published in ETHICS IN INTERNATIONAL MANAGEMENT (B. Kumar \& H. Steinmann eds., 1998).

The section, "Three Forces Influencing Business Ethics in Russia," is excerpted from our 1995 Article, "Finding the Common Ground in Russian and American Business Ethics," and is reprinted with the permission of the California Management Review and the Regents of the University of California.

Sheila M. Puffer is a Professor of International Business and Human Resources Management at the College of Business, Northeastern University, in Boston, MA. She received her Ph.D. in Business Administration from the University of California, Berkeley.

* Daniel J. McCarthy is the Philip R. McDonald Professor of Business Administration at the College of Business Administration, Northeastern University, in Boston. He received his D.B.A. in Strategy and Finance from Harvard University.

1 See David H. Holt et al., Constraints on Capitalism in Russia: The Managerial Psyche, Social Infrastructure, and Ideology, CAL. MGMT. REV., Spring 1994, at 124, 124-25; John F. Veiga et al., Emerging Cultural Values Among Russian Managers: What Will Tomorrow Bring?, BUS. HORIZONS, July-Aug. 1995, at 20, 21-22. 
environment, no single set of business ethics has yet emerged. Some observers describe at least two distinct sets of ethics, one which blatantly disregards ethical constraints, and another which observes generally accepted universal ethical norms. ${ }^{2}$

The prevailing unstable situation calls into question the future of Russian values and behaviors, including those affecting business practices and their ethical underpinnings. Various scenarios have been visualized which are plausible directions for Russian business given the present uncertainties of ethical boundaries. One analyst summarized two possible scenarios focusing upon the criminal element. $^{3} \quad$ An optimistic scenario emphasizes the need for patience while the criminal element evolves toward more mainstream behavior. This group could emerge as a cadre of "rough-and-ready entrepreneurs of contemporary Russia," much like the "robber barons" of nineteenth century America. A more pessimistic scenario emphasizes that the criminal element emerged in unique historical circumstances for an industrialized country: the capital stock passed from the State into the hands of these private individuals, as well as government apparatchiks. Neither of these groups created the wealth they accumulated through this process. This second scenario concludes that it would be a long time, if ever, before these powerful groups would yield to the forces of a free market and engage in more legitimately-based business activities.

Expanding upon these useful observations, different ethical principles could be attributed to various groups in Russian business. A disregard for ethical norms is clearly obvious among those involved in the criminal mafia that is so pervasive in the Russian economy. In contrast, managers in state-owned enterprises, as well as government apparatchiks, could be seen as deriving ethical principles from their experience in communist times. A third group of people who became involved in business activities only after the transition to the market-oriented economy might exhibit behavior seemingly based only on situational ethics.

While these groups are clearly distinct in Russian business, to

2 See generally ROBERT ANDERSON \& PETER SHIKHIREV, “AKULY" I "DEL'FINY:" PSIKHOLOGIIA IETIKA ROSSIISKO-AMERIKANSKOGO DELOVOGO PARTNERSTVA (1994).

${ }^{3}$ See Loren Graham, Message from the Acting Director, RRC NOVOSTT: THE NEWSLETTER OF THE RUSSIAN RESEARCH CENTER (Harvard University, Cambridge, Mass.), Fall 1995, at 1, 2. 
attribute a common ethical framework to all members within a single group would be inaccurate and would not facilitate an understanding of the behavior and business practices of managers and entrepreneurs. It is perhaps more realistic and useful to look beyond group identification and, instead, to analyze the forces which have shaped the ethical mindsets of individuals. ${ }^{4}$ Various influences may have affected the ethics and behavior of different individuals at different times in the past, and they continue to do so in the present turbulent and changing environment. The result is that different ethical behaviors may prevail at different times for the same individual, and certainly among individuals within the same group. In short, there has been virtually no stable state for ethical principles for many people participating in Russian business. Instead, these Russian business people have been pulled in many directions by competing forces, some of which prevailed at one time, while others took precedence on other occasions. For instance, a negative perception of entrepreneurs prevailed during most of Russia's history but they enjoyed greater acceptance during the transition period. ${ }^{5}$

These often-competing forces, which have shaped the ethical principles and business practices that ensued, are a primary focus of this Article. They will be discussed following an overview of Integrative Social Contracts Theory.

\section{INTEGRATIVE SOCIAL CONTRACTS THEORY}

Our analysis of business ethics in Russia applies the framework of Integrative Social Contracts Theory. ${ }^{6}$ This framework emphasizes the importance of universal hypernorms - such as core human rights, respect for human dignity, and good citizenship - which are ethical principles fundamental to human existence. ${ }^{7}$ As such, these hypernorms constitute the minimum threshold for ethical behavior. These over-arching principles,

4 See Sheila M. Puffer et al., Meeting of the Mindsets in a Changing Russia, Bus. HORIZONS, Nov.-Dec. 1996, at 52, 52.

5 See Daniel J. McCarthy et al., The Resurgence of an Entrepreneurial Class in Russia, J. MGMT. INQUIRY, June 1993, at 125, 126.

6 See generally Thomas Donaldson \& Thomas W. Dunfee, Toward a Unified Conception of Business Ethics: Integrative Social Contracts Theory, 19 ACAD. MGMT. REV. 252 (1994).

7 See Thomas Donaldson, Values in Tension: Etbics Away from Home, HARV. BUS. REV., Sept.-Oct. 1996, at 48, 53-54. 
however, coexist with specific norms established and accepted within various communities or groups. Communities are "self-defined, self-circumscribed group[s] of people who interact in the context of shared tasks, values, or goals and who are capable of establishing norms of ethical behavior for themselves." "While specific community norms may be different for different communities and may conflict with one another, they can be seen as legitimate within their community when they are freely adopted through micro-contracts among group members and do not violate hypernorms. Micro-contracts "represent[] agreements or shared understandings about the moral norms relevant to specific economic interactions."

An important feature of Integrated Social Contracts Theory is that different behaviors are recognized to coexist among different communities. When conflicts arise between norms, six criteria proposed in the theory can be applied to help resolve them. These six rules, presented in Appendix 1, must be applied as a set, with no a priori assessment of relative importance among them. After applying these principles to a given situation, the legitimacy of a community's norm can be established, even if it is in opposition to legitimate norms of other communities. This framework is particularly applicable to the assessment of transactions among Russians within the transitional business environment, as well as situations in which Russians conduct business with people from other countries. Russia's unique history and culture, as well as the turbulent transition to a market economy, underscore the value of such an approach.

\section{THREe ForCes INFLUENCING BUSINESS ETHICS IN RUSSIA}

This section summarizes some of the most important forces influencing the development of Russia's business ethics and is excerpted from our earlier work on this topic. ${ }^{10}$ The forces which will be discussed are: (1) the culture, history, and religion of Russia; (2) communist ideology and the centrally-planned economy; and (3) Russia's present transitional environment,

${ }^{8}$ Donaldson \& Dunfee, supra note 6, at 262.

9 Id.

${ }^{10}$ See Sheila M. Puffer \& Daniel J. McCarthy, Finding the Common Ground in Russian and American Business Ethics, CAI. MGMT. REV., Winter 1995, at 29, 32-34. 
including the legal system, government policy, and social values.

Russia's turbulent history has been characterized by oppressive political regimes that have created confusion about the role and importance of business in Russian society, as well as conflicting standards of ethical business behavior. This history, coupled with the recent turmoil created by the move toward a market economy, has created ambiguity among business people about what constitutes ethical behavior. Unfortunate personal consequences of such ambivalence have included the growing number of business people with psychiatric and addictive problems stemming from moral conflicts. ${ }^{11}$

The important and often conflicting influences contributing to this uncertainty and ambiguity surrounding standards of ethical business behavior include the high value placed on strong authority and collective behavior in traditional Russian culture, communist ideology, and the country's political and legal structures.

Russian culture, over the centuries, is replete with ruling elites and authority figures who tightly controlled society and suppressed personal freedom. Among these figures were leaders of the Russian Orthodox Church, tsars, landowners, and the Communist Party elite. The population was subjugated to the values and behaviors of these leaders, regardless of who was in control of the country. The continuous lack of individual freedom that resulted, as well as the pervasiveness of social and economic control, strongly shaped Russian values. The Russian Orthodox Church imbued Russians with Christian values, such as obeying the golden rule. However, unlike the Protestant Church, the Russian Orthodox Church did not value work as a religious virtue. Thus, people who engaged in business were often suspected of having selfish and, implicitly, unethical motives.

Instead, the Russian Orthodox Church emphasized deference and obedience to its doctrine and religious authority figures, thus reinforcing obedience to authority rather than individual responsibility. Collective values were another fundamental element of religious doctrine, and people were encouraged to subjugate personal interests to the common good. The political environment under the tsars and the economic power of the landowners

11 See Peter N. Shikhirev, Ethics, Psychology and Business in Russia (1993) (unpublished manuscript, on file with the author). 
were grounded in the same autocratic and oppressive philosophies. In summary, Russians experienced an all-encompassing environment of central control, oppression, and the lack of individual freedom and opportunity for centuries.

The situation changed little under communist rule, whose ideology provided a second major influence on Russian ethics. Centralized authority, subjugation of the individual, political and economic oppression, and collectivist values predominated. The Communists, however, tried to instill a work ethic in the general population to serve communist goals, and designed a reward system that recognized collective rather than individual achievements. Thus, individuals had little incentive to work hard or take personal responsibility for their actions. Even the collective rewards were not perceived as equitable by many people who became disillusioned with this, as well as other broken promises of material and psychic gratification.

The communist philosophy was distilled in 1962 into a twelve point moral code intended to guide the ethical behavior of loyal Communists. ${ }^{12}$ In some respects, the code was similar to the ten commandments of the Judeo-Christian tradition, but was modified to reflect the atheistic communist philosophy. As in other areas of communist ideology, however, implementation of the code failed and few took it seriously. The nomenklatura (ruling Communist elite) violated it as they saw fit, justifying virtually any means, ethical or unethical, to achieve desired ends. This hypocrisy of the ruling elite created a harsh reality that encouraged people at all economic levels to break rules to survive within the rigid demands of the system. In business, it was an accepted common practice to pad production figures to give the appearance of meeting the centrally-prescribed plan and thus to obtain rewards.

Another communist goal was the elimination of status differences in society to provide more equal access to opportunities for people from all social levels. For the first time, people of peasant origin were encouraged to pursue higher education and professional and managerial job opportunities. However, this goal and others like it were subverted as the Communist Party elite became more entrenched, reserving privileges and positions of

12 See generally RICHARD T. DEGEORGE, SOVIET ETHICS AND MORALITY (1969). 
influence for themselves. These actions reinforced the fact that ability and accomplishment were not the determining factors for success. Rather, Communist Party membership and loyalty provided the status which became necessary to achieve power and privilege within society. The Communists effectively emerged as the new ruling elite.

A third major influence on the development of Russian business ethics has been the country's political and legal structures and institutions. Much of the political environment under the tsars and Communists has been discussed above, the primary characteristics being centralized dictatorship, oppression of individual expression, and little freedom or opportunity for most of the population. The result was a passive and obedient population with little tolerance for individual accomplishment, business activities, or entrepreneurship. In the legal environment, laws and edicts were dictated by tsarist and communist authorities with little opportunity for dispute, and trial by jury did not exist. Under Communism, there were so many meaningless, and often contradictory, laws and regulations governing business activities that managers had to become adept at circumventing them in order to meet the unrealistic goals assigned by central authorities. ${ }^{13}$ This was a widely accepted practice, and even central authorities looked the other way, since it was not considered a serious violation, but simply a pragmatic way of doing business. Nevertheless, flagrantly criminal behavior, such as major theft of company property, as well as serious breaches of communist ethics, such as disloyalty to the Party, were severely and publicly punished.

The legalization of private enterprise in the late 1980 s became a major source of widespread ethical confusion. Communist philosophy did not recognize the existence of private property or profits, yet both became legalized, and even mandated, by Soviet and Russian laws. Many such laws were passed within the context of the developing free enterprise system. They often contradicted one another, were frequently amended or rescinded, and were inconsistently enforced.

This chaotically-evolving legal structure gave little direction to people engaged in business. Individuals had to define for them-

13 See generally JOSEPH S. BERIINER, SOVIET INDUSTRY FROM STALIN TO GORBACHEV (1988). 
selves the proper conduct in business relationships. These business people came from different backgrounds and often held different values. Among those who entered the business world were managers of state enterprises, former high-ranking Party officials, academics, students, other professionals, and black marketeers. Some business people were guided by the values and accepted practices of the former communist system, others by universal values or religious beliefs, and others by criminal and unscrupulous motives. Still others, lacking experience in a market economy, simply were ignorant of what constituted ethical behavior in such radically new and uncertain circumstances.

\section{ApPLyING THEORY to PRACTICE}

To analyze the ethical legitimacy of several current business practices in Russia, we have applied the Integrative Social Contracts Theory to six common situations which many observers would consider ethically questionable in one sense or another. We have particularly emphasized the six principles for resolving conflicts between shared values of specific communities within Russian business, or business communities in other countries. We have also integrated the effects of the primary forces that have shaped values within these different communities. By doing so, we have attempted to clarify the ethical appropriateness of these six particular business practices. These practices and their relationship to the six principles for resolving ethical conflicts are summarized in Appendix 2.

We first apply the theory to three highly questionable practices in Russia: extortion, managerial buy-outs of enterprises, and the breaking of contracts. These practices would be considered by many to violate universal hypernorms as well as the norms of most communities in Russia. Our evaluation of these practices, utilizing the six principles, leads us to the conclusion that they are clearly unethical behaviors. Three additional practices, ignoring arbitrary or senseless laws, using personal favoritism or blat, and laying off employees, do not violate hypernorms, and we assume that the conflicting community norms are legitimate in the Donaldson and Dunfee sense. Since the ethicality of these practices can be ambiguous in some communities, however, the six principles are especially helpful in drawing conclusions. With the exception of employee layoffs, which remains an ethically ambiguous practice, the latter three 
practices do not seem to violate community norms in Russia and generally seem to be ethical there.

\subsection{Extortion}

Extortion involves demanding money, property, or services from others through force or the threat of force. It is illegal, as well as unethical, in virtually all societies. Extortion violates hypernorms, such as respecting core human rights like the ownership of property and the dignity of other human beings. Various forces have shaped such hypernorms. For Russia these include the country's history and culture, the Orthodox Church, and communist ideology. Even in the turbulent environment of Russia's transition to a more open society and market-oriented economy, the practice is considered illegal and immoral.

However, extortion and similar activities were pervasive in the transitional Russian business environment. ${ }^{14}$ Many private enterprises and commercial banks were reported to pay an extortion "tax" to the mafia, amounting to ten to twenty percent of their sales. ${ }^{15}$ Virtually all Russian business communities condemn such practices. Yet, because of the pervasiveness of the criminal mafia, and the acceptance of such practices within their community, many might consider such behavior to be "ethical" when dealing with rival mafia members. Such behavior within the mafia would likely be considered unethical by virtually everyone outside the mafia, and we have applied the principles to illustrate why this is so. In summary, this first application of the principles will explain the unethical nature of extortion and illustrate the utility of the framework by analyzing this obvious breach of ethics.

Extortion is repugnant to most people since it violates the hypernorms of respecting human dignity and personal safety, and it is clearly unethical and illegal when mafia members extort from members of other business communities. However, when the practice is restricted to the mafia, and does not have significant direct adverse effects on other communities, it could be considered

14 See Puffer and McCarthy, supra note 10, at 29; Peter Unwin \& Vincent Carratu, The Fight Against Grand Corruption and Piracy in Eastern and Central Europe, RSA J., July 1996, at 52.

15 See ECON. NEWSLETTER (Russian Research Center, Harvard University), Apr. 10, 1994, at 4. 
acceptable within the mafia micro-contract (Rule 1). Within that community, this behavior might be the norm, and as long as other people and communities are not hurt, it might again be appropriate (Rule 2).

The unethicality of the behavior, however, becomes clearly apparent when applying the next four principles. Although a serious element threatening society, the mafia is not a very extensive community within Russia; therefore, its norms should not take precedence over those of the broader Russian business community (Rule 3). Similarly, extortion undermines the functioning of a market-oriented economy, and norms essential to maintaining the broader economic environment should have priority over economically damaging norms (Rule 4). Norms against extortion are consistent with norms against murder and money laundering, crimes which often accompany extortion (Rule 5). Lastly, well-defined norms exist against extortion to the extent that it is a crime in virtually all societies and subject to strong legal sanctions (Rule 6).

The usefulness of the six principles in evaluating questionable practices within business has been demonstrated by applying them to the blatantly unethical, but unfortunately common, practice of extortion in the Russian economy. The framework becomes increasingly useful in analyzing five additional practices with more ambiguous ethical interpretations.

\subsection{Managerial Buy-Outs of Enterprises}

Privatization in Russia allowed the ownership of many enterprises to pass from the State to private individuals. By the mid-1990s, more than 20,000 former state enterprises had been privatized, along with countless thousands of small retail shops and services. ${ }^{16}$ Policies called for distributing ownership vouchers to all workers and managers of the privatized enterprises, as well as to other Russian citizens. ${ }^{17}$ However, many managers subverted the objective, creating citizen shareholders by accumulating large percentages of shares in their own enterprises. The resulting concentration of ownership allowed them to exercise

16 See generally MaXim BOYCKO ET AL., PRIVATIZING RUSSIA (1995).

17 See Daniel J. McCarthy \& Sheila M. Puffer, "Diamonds and Rust" on Russia's Road to Privatization: The Profits and Pitfalls for Western Managers, COLUM. J. WORLD BUS., Fall 1995, at 56, 58. 
power, often to the detriment of other shareholders, the enterprises, and the Russian economy. In effect, such individuals gained most of the rights and benefits of private entrepreneurs without many of their responsibilities, and with little risk of failure. ${ }^{18}$ The privatization program even came to be dubbed by cynics as "prikbvatizatsiia" ("grabization"), a play on the word for privatization, "privatizatsia." Such self-serving behavior led one observer to conclude: "We do not see many self-made Henry Fords among our new rich. Instead we see the main tools for getting rich are insolence, moral compromise, abuse of one's position within the country's power structures, and crime. ${ }^{19}$

Historically, in feudalistic Russian society, private property was only available to wealthy landowners and members of the aristocracy. Privately-owned factories employing hired labor appeared in the mid-nineteenth century, but the serfdom that prevailed until that period greatly restricted the notion of private property. ${ }^{20}$ In addition, anti-capitalist sentiment was a strong tradition among many social classes in pre-communist Russia. ${ }^{21}$ During the communist period, private property was outlawed, with the State assuming ownership of land, real property, and the means of production. Power resulted from the privilege of position, rather than ownership of property. Abuse of this power resulted in Party members, and other privileged people, receiving favors, goods, and services unavailable to others. Later, privatization, a cornerstone of the transition to a market economy, was an attempt to distribute ownership of enterprises to Russian citizens. In practice, however, ownership became concentrated in the hands of opportunists, including enterprise managers, who saw that ownership of their enterprises could bring them control, power, and wealth.

Abuses resulting from such managerial buy-outs negatively

18 See generally Igor Filatotchev et al., The Ethical Challenge of Management Buy-outs as a Form of Privatisation in Central and Eastern Europe, $13 \mathrm{~J}$. BUS. ETHICS 523, 529 (1994) (explaining that "the development of voucher buy-outs will inevitably be followed by substantial income redistribution in favor of managers and employees at the expense of the broader society").

19 Konstantin Zuyev, MOscow TIMES, July 23, 1995.

20 See M.E. FALKUS, THE INDUSTRIALIZATION OF RUSSIA, 1700-1914 43 (1972); ARCADIUS KAHAN, RUSSIAN ECONOMIC HISTORY 5-8 (Roger Weiss ed. 1989).

21 See THOMAS C. OWEN, RUSSIAN CORPORATE CAPITALISM FROM PETER THE GREAT TO PERESTROIKA 10 (1995). 
affected many workers, other shareholders, and Russian citizens, while violating the spirit and intent of the privatization laws. Such buy-outs also violated norms of the broader Russian society, which deemed such behavior unfair since these individuals did not earn or create the wealth they acquired. In this sense, such behavior violated the norms of the broader host community (Rule 1). Because these behaviors adversely affected other Russian citizens in a significant way, they could not be considered legitimate (Rule 2). Also, since they violated the norms of the broader Russian society, they should be considered secondary to those more widely-held norms (Rule 3). Perhaps the most compelling argument against the abuse of ownership rights is that these practices have the potential to undermine the emerging economic system by unfairly controlling assets (Rule 4). Although abuse of power has long existed in Russia, it has never been viewed as legitimate. The overwhelming preference in society has been for behavioral norms which condemn these abuses. Included would be norms of basic fairness and honesty (Rule 5). These pervasive and well-defined norms should clearly take priority over the opportunistic behavior of some managers during the period of privatization (Rule 6).

Taking the six principles in totality, the behavior of many Russian managers who bought control of their enterprises during the privatization period, often at extremely low prices, would be considered by virtually all observers as unethical, even in cases where the practice was legal. This behavior clashes with many well-established norms of Russian society which call for fair and just behavior in transactions with others, dependability in one's word and contracts, and not taking unfair advantage of others who lack information or ability to properly exercise their rights. The uncertainties of new situations, such as ownership of private property, and especially of paper shares, created opportunities for some to benefit at the expense of others. In this transition economy, the abuse of power by managers, who exploited others and took ownership of their shares in the process, could not be considered legitimate. Regardless of uncertainties, radical change, and even the possible legality of some of their actions, the negative effects on so many others must be the major basis for legitimacy. The well-established norms of Russian society would clearly label the actions of these opportunistic individuals as unethical. 


\subsection{Breaking Contracts}

Breaking contracts has become more common in the transitional economy, in contrast to the importance historically given to honoring contracts in Russia. A highly visible example which affected most Russian enterprises and their workforces during this time has been the government's nonpayment of its debts to enterprises, interfirm debt, and the ensuing delays in paying wages for as long as six months. The head of the Russian Orthodox Church, Patriarch Alexiy II, voiced the Church's grave concern about this issue:

We urge the leadership of the country ... and all those responsible for the non-payment of pensions, wages and student grants to recognize the urgent need for resolution of this problem,"... A At all times the Church has been and remains on the side of the weak and the unfortunate ... it cannot fail to raise its voice in defense of those who find themselves on the brink of life and death as a result of tragic impoverishment."22

Although perhaps less pervasive than nonpayment of wages and debts, the breaking of various types of business contracts had become more common during the chaotic transitional environment.

Historically, the 1832 Russian Civil Code provided a basis for the legitimacy of contracts. Even in communist times, the State prepared "form" contracts in which, for instance, agreements between Soviet foreign trade organizations and foreign firms were spelled out in specific terms. ${ }^{23}$ Soviet negotiators were generally viewed as reliable, and international arbitration was utilized to resolve disputes with foreign organizations. During the market transition, the validity of contracts was confirmed by passage of a new Western-style commercial code which enabled companies to seek legal recourse through such bodies as the Moscow

22 Russia's Patriarch Slams Poverty, Wage Arrears, Reuters, Jan. 6, 1997, available in LEXIS, News Library, Curnws File.

${ }^{23}$ See Randy Bregman \& Sarah Carey, Contracting in Russia: Not Perfect, but it Works, RUSSIA BUS. WATCH, Winter 1995, at 1, 41-42. 
Arbitration Court. However, even though the Court sometimes ruled in favor of Western parties, it was not uncommon for implicated Russian companies to ignore the rulings. ${ }^{24} \mathrm{~A}$ complicating factor in enforcing contracts was that shareholder approval was frequently required before a contract could be signed. Yet, it was often nearly impossible to determine legitimate ownership of many enterprises.

Applying the six principles of Integrative Social Contracts Theory, Rule 1 indicates that contracts between members of Russian business communities should be honored, given the historical and cultural bases for doing so, even though the uncertainties which arose during the market transition often made it difficult. Likewise, the wide acceptance of honoring contracts would take precedence in conflicts about such issues (Rule 2). And the same conclusion ensues given the acceptance by the broader Russian society of the need to honor contracts, as well as to keep other promises (Rule 3). The sanctity of contracts is also fundamental to maintaining stability and predictability in the economic environment in which Russian businesses must function (Rule 4). And the norm of honoring contracts is consistent with others, such as keeping one's word and maintaining trust (Rule 5). Lastly, the norms against breaking contracts are well-defined and also supported by laws (Rule 6).

Applying the six principles, breaking contracts is consistently seen as unethical, and usually illegal. The norm of honoring contracts is well established in Russian business communities and supported by broadly accepted social and cultural norms. Complicating factors, however, emerged in the transitional economy. Managers encountered extreme pressures when the government ceased paying subsidies and even debts to enterprises. An acute cash shortage arose among enterprises and resulted in trillions of rubles of interfirm debt and unpaid workers' wages. Recognizing their obligations, many managers reverted to the traditional practice of bartering goods and services to pay debts and wages.

Although such resourcefulness could not always enable managers to pay all their enterprise debts, it would be wrong to

${ }^{24}$ See Richard Steffens, Resolving Commercial Disputes, BISNIS BULL., Sept. 1996, at 1 (noting that Russian companies have been known to "ignore the findings of the court and refuse to pay"). 
label their behavior as illegitimate or unethical as long as they attempted to fulfill obligations. Such severe situational constraints must be taken into account when interpreting behavior in the turbulent transitional society. Failure to honor contracts is clearly considered to be unethical in the Russian business community, but it could come to be viewed as legitimate in extreme circumstances.

\subsection{Ignoring Arbitrary or "Senseless" Lawes}

Arbitrary laws are those which do not make sense to business people because they are viewed as interfering with the effective functioning of the business environment. Given the circumstances they have faced over time, business persons have applied what some observers might view as situational ethics to justify ignoring or circumventing laws considered to be arbitrary.

The reasons for this behavior can be attributed to several influences. Historically, citizens have been faced with oppressive laws imposed by authorities such as landowners, tsars and communist officials. Many laws have imposed heavy taxes and restricted freedom, such as the gentry's charter of 1785 which empowered landowners to collect taxes from peasants. ${ }^{25}$ Since compliance with such laws was often a threat to personal survival and well-being, people developed a view that it was acceptable to circumvent or ignore such laws and regulations. This mentality led the nineteenth century Russian observer Shedrin to remark that bad laws are compensated for by the fact that no one pays attention to them. Also, the practice of landowners padding their records with the names of dead serfs to obtain land was immortalized in Gogol's nineteenth century novel, Dead Souls.

Many laws and requirements established during the communist period were seen by managers as being adverse to running their enterprises and preventing them from gaining rewards, such as bonuses allocated by central ministries. This led to practices, such as manipulating data in reports to central authorities, exceeding inventory limits by hoarding, and hiring bloated work forces in excess of authorized numbers. ${ }^{26}$ In addition, accounting practices were centrally-controlled with the audit function being more of a government inspection than an independent financial audit in

25 See RONALD HINGLEY, RuSSIA: A CONCISE HISTORY 89 (1991).

26 See BERLINER, supra note 13, at 89-90. See generally ALEX INKELES \& RAYMOND A. BAUER, THE SOVIET CITIZEN (1959). 
the Western sense. ${ }^{27}$ In the transitional economy, conflicting and inconsistently-enforced laws and regulations led business people to continue ignoring and circumventing them. For instance, the accumulation of numerous tax laws could have required enterprises to pay taxes exceeding $100 \%$ of profits, resulting in tax arrears in early 1997 that were estimated at twenty-three billion dollars. ${ }^{28}$ However, many business people became so adept at legally avoiding the payment of taxes on their profit that the tax police could often not find fault with their methods. This was especially true when such taxes threatened the survival of a business. ${ }^{29}$

The practice of ignoring senseless laws and regulations has been pervasive in the broader Russian society, and consequently is an accepted norm within the business communities. Thus, when laws contradict each other or prevent the reasonable functioning of business, it may be illegal to ignore them, but such actions cannot be considered unethical (Rule 1). The norms within the business communities show a distinct pattern of circumventing laws to resolve conflict-of-norms situations. Barring significant adverse effects on other communities within Russia, such as the nonpayment of taxes seriously threatening the government's functioning, these actions could be considered legitimate (Rule 2). As in Rule 1 above, the practice of ignoring arbitrary laws and regulations is generally accepted within Russian society. Therefore, this global norm would likely be accepted in the business communities (Rule 3).

However, a clear danger to the developing economic system could emanate from the practice of ignoring so-called arbitrary laws and regulations. Understandably, business persons might ignore these laws and regulations and put their own interests first. This could lead to a weakening of the economic and governmental structures necessary to the development of a market economy. As such, ignoring laws might come to be viewed as unethical (Rule 4). Although ignoring laws comes into conflict with the norms

${ }^{27}$ See Margaret T.R. King, The Challenge to Accounting in Eastern Europe, BUS. \& CONTEMP. WORLD, 1994, at 112-21.

28 See Janet Guttsman, Russian Economic Problems Remain after IMF Handout, REUTERS, Feb. 9, 1997, available in IEXIS, News Library, Curnews File.

29 See generally Lidia Lukyanova, Will Russia Get a "Smarter" Tax Policy?, PRISM, Nov. 1996. 
of respecting authority and obeying laws, Russia's history and culture have produced other norms such as buying favors and turning a blind eye to the theft of State property. The latter practice became more entrenched as legitimate during the build-up of the communist welfare state when norms shifted from those of sacrifice to those of entitlement. ${ }^{30}$ These new norms formed a consistent pattern of behaviors designed to protect personal survival and well-being rather than to unquestioningly follow the mandates of higher authorities. As part of such a pattern of acceptable behavior, ignoring senseless laws and regulations could be considered legitimate (Rule 5). And as with personal favoritism, when deciding ethicality, this set of well-defined norms should take precedence over other conflicting or developing norms (Rule 6).

Using the six principles for resolving conflict among ethical norms, the practice of ignoring senseless laws is likely to be considered legitimate in most circumstances. Russia's authoritarian history and repression of individual freedom have given legitimacy to this and other related practices. Such behavior by individuals might have been considered acceptable, and even ethical, during the transition period. In totality, however, it may become destructive to the functioning of a market economy and work to the detriment of Russian citizens. If such a situation were to materialize, a plausible scenario as the transition continues, the practice will likely come to be viewed as unethical.

\subsection{Personal Favoritism or Blat}

Personal favoritism, known as blat, involves "reliance for favors upon personal contacts with people in influential positions." ${ }^{31}$ Blat takes many forms, such as giving money, goods, or services to people in power in exchange for something of value, such as a job, promotion, contract, or access to influential people. Securing a favor sometimes involves payments to a series of individuals who are instrumental in gaining access to the final decision maker. Blat has been a common practice in Russia for centuries. However, it is considered bribery and is illegal when large amounts of money are involved or when highly placed

${ }^{30}$ See Donna Bahry, Society Transformed? Retbinking the Social Roots of Perestroika, 52 SLAVIC REV. 512, 551 (1993).

${ }^{31}$ Puffer \& McCarthy, supra note 10 , at 37. 
authorities blatantly abuse their power. A number of tax collectors, for instance, have been prosecuted during the transition for taking large bribes from taxpayers in exchange for favorable treatment. ${ }^{32}$

Historical conditions which encouraged blat include the expectation that serfs bring gifts to their landowners to gain favor and avoid sanctions. In the broader Russian society, gift giving has traditionally been widely accepted and expected, with gifts frequently exchanged in both business and personal relationships, such as when visiting companies or homes. Gifts help to bind friendships, gain cooperation, and secure specific favors. Severe shortages of goods and limited opportunities for individual rewards during the communist period further contributed to the use of blat. For instance, individuals would exchange favors, such as accepting goods from an enterprise manager in return for facilitating his child's admission to a university. In the market-oriented economy, blat may be used to improve one's business by gaining preferential bank financing, special terms in contracts, or to gain access to important customers.

Because blat has been so pervasive within Russian society, it could also be considered a norm of the business communities, and thus ethical (Rule 1). Similarly, community norms do not bring blat into conflict with other norms. Thus, it is considered legitimate until it reaches the point of being illegal bribery (Rule 2). As with Rule 1, the broader community's endorsement of gift giving is consistent with the practice of blat in business (Rule 3). Blat in itself is not damaging to the economic system of Russia, and may even facilitate business transactions in a traditionally bureaucratic society. Thus, it can be considered legitimate unless it would harm the economic system, such as when bribery occurs (Rule 4). The practice of blat is consistent with other norms that are considered ethical, including building networks of relatives and friends who are reliable and trustworthy, as well as refraining from whistleblowing to protect oneself and others against the arbitrary use of power and punishment by authorities.

While blat would be considered by many Russians to be inconsistent with the norm of basic fairness, the oppressive conditions under which they live has promoted blat as a necessity

32 See LeV Rudskin, PODAROK . . . VZIATKa [GIFT . . . BRIBE], NOVOE RUSSKOE SLOVO [NEW RUSSIAN WORD], July 20-21, 1996, at 17. 
for survival (Rule 5). Blat has long been a well-defined norm and is accepted as almost inevitable given the lack of freedom and opportunity under oppressive political regimes (Rule 6).

Applying all six rules, blat emerges as an accepted and generally legitimate practice within Russia that developed as a mechanism for survival under harsh conditions. However, many Russians would consider it to be unfair, and would likely view it as unethical under other circumstances. As Russia becomes a market-based economy, tied more tightly to the global economy, the ethicality of blat is likely to come into question. For instance, the U.S. Foreign Corrupt Practices Act, which regulates America$n s^{\prime}$ business practices, would likely limit the use of blat by Russians in transactions with Americans.

\subsection{Employee Layoffs}

Laying off employees, especially mass layoffs, historically has been considered unethical in Russia. During the market transition, many Russian enterprises resisted layoffs, realizing that they would result in large-scale unemployment, as well as the possibility of political and social unrest.

The historical custom whereby patriarchical landowners took responsibility for the well-being of the serfs who worked their land influenced this norm. Likewise, the church provided care for people and affirmed the right of individuals to secure their living. During the communist period, all citizens were entitled to a job and most were obligated by the state to work. The unstable market transition, however, has profoundly influenced attitudes toward layoffs and resulting unemployment in business communities. In short, the desperate condition of many Russian enterprises, especially the large obsolete and uncompetitive state-owned and partially-privatized firms, necessitated massive layoffs, resulting in an estimated ten percent annual unemployment rate from 1991 through 1996. ${ }^{33}$ This situation was dramatically different from earlier periods, and thus much ambivalence and uncertainty developed about the ethicality of laying off employees.

Applying the principles of Integrative Social Contracts Theory, layoffs would be considered unethical because of the adverse effects on those laid off (Rule 1). Community norms in Russian

${ }^{33}$ See generally GUY STANDING, RUSSIAN UNEMPLOYMENT AND ENTERPRISE RESTRUCTURING (1996). 
society would show a preference for maintaining employment, but business realities might mandate layoffs for enterprise survival, as well as continued employment for a smaller number of employees (Rule 2). Thus, this rule in itself does not conclusively resolve the ethical conflict, particularly during the difficult transitional economy. Rule 3, however, recognizes the legitimacy of norms emanating from the broader community, and thus would lead to the conclusion that layoffs are unethical. Norms which maintain the economic viability of a society (Rule 4), however, suggest that layoffs are sometimes necessary for firms to survive. State enterprises have been notorious for their bloated work forces whose high cost and inefficiency necessitate layoffs during the new period of market competition.

Regarding consistency among norms (Rule 5), during the communist period, guaranteed employment was consistent with other aspects of social policy, such as free education and medical care. In the transitional economy, however, such consistent norms no longer existed and citizens had to pay for education, health care, and other services beyond severely reduced government benefits. ${ }^{34}$ Changes such as these created confusion among Russians as to what constitutes ethical practices. Because previously well-defined norms about layoffs no longer existed, situational norms developed in their place, causing much uncertainty to the interpretation of ethical behavior (Rule 6).

Taking all six rules into account, no clear resolution emerges as to the ethicality of laying off workers in Russia, and each instance must be evaluated in its own context. People influenced primarily by the values of the past would likely view layoffs as unethical, while those with business experience only in the emerging market economy would almost certainly feel otherwise.

\section{CONCLUSION}

In this Article, six selected business practices in Russia have been analyzed by applying Donaldson and Dunfee's Integrative Social Contracts Theory. The turbulence in Russia during the transition to a market economy has produced a number of practices which would likely be considered unethical when applying the hypernorms common to many societies. Yet other

${ }^{34}$ See generally LINDA J. COOK, THE SOVIET SOCIAL CONTRACT AND WHY IT FAIIED (1993). 
practices, while not violating hypernorms, are questionable from an ethical perspective. The value of the Integrative Social Contracts framework lies in its flexibility which requires not only looking at ethical hypernorms, but also requires that the norms of individual communities be considered when evaluating behaviors and practices.

The six principles of this theory also take into account various influences on specific communities when judging the legitimacy of business practices, especially when these practices come into conflict with more broadly accepted norms of other communities. Using this methodology, the historical norms of that broader community, as well as changes in those norms, should be considered when evaluating business practices. For instance, although there has been much consistency in values during the lifetimes of most Russians, changes in social standards and values in the Stalin era and beyond have been initiated by the younger and better educated generations. ${ }^{35}$ These generational shifts, which encompassed the desire for change and rising expectations, continued into the post-perestroika period, creating new standards and values more consistent with a market-oriented economy.

There have been a number of important business developments in Russia. For instance, employee layoffs have gained broader acceptance. In addition, members of the nomenklatura, whose activities were often closely tied to the mafia in the early transition stages of accumulating wealth, later distanced themselves from the criminal element in pursuit of more legitimate status and business practices. ${ }^{36}$ It has been estimated that eighty-seven percent of such Russians have followed this course. ${ }^{37}$ Although the positive scenario, noted at the beginning of this Article, of the criminal mafia moving toward more legitimate business practices may not be in the offing, it is still encouraging that many former members of the nomenklatura have chosen to do so.

As Russia becomes more active in the world economy, its business laws and practices are likely to become increasingly influenced by, and aligned with, the norms of the broader international economic order. For instance, in 1996 the U.S.

35 See Bahry, supra note 30, at 549-55.

36 See DMITRY MIKHEYEV, RUSSIA TRANSFORMED 156 (1996).

37 See Olga Kryshtanovskaia, Portrait of the Contemporary Business Elite, DELOVOI MIR, Dec. 28, 1994, at 9. 
ambassador to the Russian Federation, Thomas Pickering, predicted that "within three years Russian tax laws and accounting standards are going to approach Western norms' and 'Russia will be one of America's top trading partners."m38

If positive developments continue to occur, increasing numbers of people from around the world will engage in business transactions with Russians. They should realize that Russia, like other countries, will continue to have its own unique set of norms and standards for ethical behavior. To expect otherwise would be unrealistic given the variations in ethical norms among countries, and the unique influences of Russia's history, politics, and culture. When evaluating the norms and ethics of various Russian business communities, the reasons for questionable or confusing business practices must be understood. Techniques like the Integrative Social Contracts Theory provide a more thorough and fair ethical evaluation of Russian business practices than is possible by judging them according to a set of preconceived standards.

38 Padraic J. Sweeney, A Veteran Observer, BISNIS BuLL., Nov. 1996, at 2. 
APPENDIX 1

Six Principles for Evaluating the Ethicality of Behavior ${ }^{39}$

Rule 1. Transactions solely within a single community, which do not have significant adverse effects on other humans or communities, should be governed by the host community's norms.

Rule 2. Community norms indicating a preference for how conflict-of-norms situations should be resolved should be applied, so long as they do not have significant adverse effects on other humans or communities.

Rule 3. The more extensive or more global the community which is the source of the norm, the greater the priority which should be given to the norm.

Rule 4. Norms essential to the maintenance of the economic environment in which the transaction occurs should have priority over norms potentially damaging to that environment.

Rule 5. Where multiple conflicting norms are involved, patterns of consistency among the alternative norms provide a basis for prioritization.

Rule 6. Well-defined norms should ordinarily have priority over more general, less precise norms.

39 The following six Rules are taken verbatim from Donaldson \& Dunfee, supra note 6 , at $269-70$. 


\section{APPENDIX 2}

Evaluating the Ethicality of Six Questionable Russian Business

\section{Practices}

Principles for Evaluating Behavior

Business Practice

$\begin{array}{lllllll}1 & 2 & 3 & 4 & 5 & 6 & \text { Conclusions }\end{array}$

1. Extortion $U \quad U \quad U \quad U \quad U$ U Unethical

2. Managerial Buy-Outs $U$ U $U$ U $U$ U Unethical

3. Breaking Contracts $U$ U $U$ U $U$ U Unethical

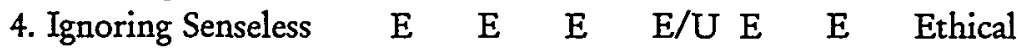
Laws

5. Personal Favoritism E E E E E/U E Ethical (Blat)

6. Layoffs $U$ E/U U E E/U E/U Ethical/ Unethical

E: $\quad$ Ethical

U: Unethical

E/U: Ambiguous whether ethical or unethical 